Arq. Bras. Med. Vet. Zootec., v.56, n.2, p.222-231, 2004

\title{
Relação de risco como indicador do número de animais necessário no mapeamento genético de características binárias complexas em bovinos
}

[Risk ratio as indicator of the number of animals necessary for genetic mapping of complex binary traits in cattle]

\author{
A. Thaler Neto ${ }^{1}$, R. Fries ${ }^{2}$, G. Thaller ${ }^{2}$ \\ ${ }^{1}$ Departamento de Zootecnia \\ Centro de Ciências Agroveterinárias da Universidade do Estado de Santa Catarina \\ Avenida Camões, 2090 \\ 88520-000 - Lages, SC \\ ${ }^{2}$ Technische Universität München - Freising - Alemanha
}

\begin{abstract}
RESUMO
Este estudo de simulação de dados objetiva avaliar a relação de risco $\left(\lambda_{\mathrm{R}}\right)$ como indicador do número de animais genotipados necessário para o mapeamento genético de características binárias, tais como a mastite bovina. Dados foram simulados para diferentes prevalências, modelos genéticos e seus parâmetros, em famílias com aproximadamente cinco meios-irmãos afetados. Analisaram os dados gerados em pares de meios-irmãos afetados ("affected sib pairs analysis"). O número necessário de famílias genotipadas aumenta com a prevalência, enquanto os valores de $\lambda_{R}$ decrescem, validando $\lambda_{R}$ como indicador do número de animais necessário para o mapeamento para diferentes prevalências. São necessárias mais famílias para características dominantes em relação às recessivas. Penetrância incompleta exerce pouca influência, enquanto fenocópias aumentam o número necessário de animais. Um segundo locus diminui o poder de detecção de genes, especialmente em modelos com heterogeneidade de locus. Pode-se concluir que $\lambda_{R}$ é indicador útil para determinar o número de animais necessários em experimentos de mapeamento genético com famílias de meios-irmãos.
\end{abstract}

Palavras-chave: bovino, características binárias, delineamento experimental, mapeamento genético, relação de risco

\begin{abstract}
The objective of this simulation study was to evaluate the suitability of risk ratio $\left(\lambda_{R}\right)$ as indicator of the number of genotyped animals necessary for mapping genes for binary traits, such as mastitis in cattle. Data were simulated for different prevalences, genetic models and parameters of these, in families with five affected halfsibs in average. The data were analyzed with methodology of "affected sib pairs". The number of genotyped halfsib families needed increase with the prevalence. As risk ratio is lower with higher prevalences, $\lambda_{R}$ is an adequate indicator for comparing power for traits with different prevalences. The number of animals needed was substantially higher for dominant as for recessive traits. Incomplete penetrance had little influence on the power, but phenocopies increase the number of needed animals. The presence of a second locus decreased the power especially in genetic models with locus heterogeneity. It can be concluded that $\lambda_{R}$ is a useful indicator to determine the number of animals necessary in mapping experiments in halfsib families.
\end{abstract}

Keywords: binary traits, cattle, experimental design, genetic mapping, risk ratio

Auxílio financeiro: CNPq e Universidade do Estado de Santa Catarina (UDESC)

Recebido para publicação em 30 de janeiro de 2003

E-mail: thaler@cav.udesc.br 


\section{INTRODUÇÃO}

O mapeamento de genes envolvidos com características de importância econômica promete novas possibilidades de obtenção de ganhos genéticos. Ganhos adicionais podem ser esperados a partir da adição de novos conhecimentos de genética molecular aos programas de melhoramento genético, especialmente em características para as quais o ganho genético obtido mediante técnicas clássicas de seleção é limitado. Dentre essas características encontram-se as de baixa herdabilidade, de aparecimento tardio, negativamente correlacionadas com outras características de importância econômica e características ligadas ao sexo. Nos últimos anos, progresso considerável tem sido obtido na elucidação da base genética de características com herança mendeliana simples, tanto no homem como nas principais espécies de interesse zootécnico. Entretanto, a identificação de regiões de cromossomos envolvidas com características complexas, denominadas economic trait loci (ETL) ou quantitative trait loci (QTL), representa uma importante tarefa da pesquisa em melhoramento genético animal. Entende-se como características complexas aquelas que não exibem herança mendeliana recessiva ou dominante clássica, sendo a etiologia genética obscurecida por fatores tais como herança poligênica, fenocópias (indivíduo apresenta a característica ou doença devido a fatores não genéticos), penetrância incompleta (nem todos os indivíduos com genótipos susceptíveis exibem a doença) e heterogeneidade genética (mutações em diferentes genes podem determinar fenótipos semelhantes) (Hodge, 1984; Lander, Schork, 1994; Terwilliger, Weiss, 1998). Considerando a onerosa execução de experimentos para a identificação de genes relacionados com características dessa natureza, o delineamento experimental deverá ser criteriosamente analisado, visando determinar o número de animais genotipados necessário para $\mathrm{o}$ mapeamento. Em função disso, torna-se necessária a estimação de parâmetros que permitam delinear experimentos de maneira mais acurada, visando aumentar a probabilidade de sucesso e otimizar a utilização dos recursos financeiros.

A probabilidade de encontrar genes relevantes depende da contribuição da variação genética em relação à fenotípica. Em características quantitativas, a herdabilidade pode ser utilizada como indicador do número necessário de animais genotipados. Para características binárias a herdabilidade pode ser estimada por modelo de limiar (Gianola, Foulley, 1983; Falconer, Mackay, 1996). Entretanto, sua estimação para fenótipos mais específicos, desenvolvidos especialmente para o mapeamento genético, é limitada, visto que para uma estimação acurada grandes amostras de dados são necessárias (Hoeschele, Tier, 1995), o que dificulta a aplicação de filtros aos dados visando a obtenção de fenótipos bem definidos, mais indicados para o mapeamento genético (Brzustowicz, 1998). Além disso, pressuposições do modelo de limiar podem ser violadas, por exemplo quando genes de efeito maior estão presentes (Falconer, Mackay, 1996), situação desejada para o mapeamento genético.

Um conceito alternativo é a relação de risco ou "risk ratio" $\left(\lambda_{R}\right)$, definido como risco de um parente de um indivíduo que apresenta determinada característica ou doença em relação à sua prevalência na população (Risch, 1990a; Lander, Schork, 1994; Thaler Neto et al., 2000). $\lambda_{R}$ é freqüentemente usado na genética humana, sendo considerado o mais importante parâmetro genético (Lander, Schork, 1994; Lui et al., 2000), visto que afeta o poder de identificação de genes em estudos de ligação gênica, envolvendo pares de parentes afetados (Risch, 1990b; Gu, Rao, 1997). $\lambda_{R}$ tem a vantagem de poder ser estimado em amostras menores de dados e não necessita de pressuposições quanto à base genética da característica para a sua estimação.

O objetivo deste trabalho foi, mediante simulação de dados, avaliar a utilização do parâmetro relação de risco como indicador para determinar o número necessário de animais genotipados para mapeamento de genes relacionados com características binárias complexas em famílias de meios-irmãos, tipicamente encontradas em bovinos.

\section{MATERIAL E MÉTODOS}

Programas em Fortran 90 foram elaborados com o objetivo de simular dados para características binárias sob diferentes modelos genéticos 
(monogênicos, digênicos e mistos) e parâmetros desses modelos.

Foram considerados dois modelos monogênicos, com herança recessiva ou dominante para susceptibilidade à doença, e três modelos digênicos, nos quais o fenótipo positivo (doente) foi atribuído quando os animais eram (a) duplo homozigotos recessivos, (b) homozigotos recessivos para no mínimo um locus ou (c) possuíam no mínimo dois alelos causais para a característica, de um ou de ambos os loci. Nos modelos genéticos mistos a escala base foi assumida como sendo continuamente distribuída com um único limiar (Falconer, Mackay, 1996), sendo simulados genes de efeito maior com herança recessiva ou dominante. Foram considerados loci bialélicos.

Foram simulados dados para características com prevalência de 5, 10 e $20 \%$, procurando simular situações de doenças comuns em bovinos, tais como a mastite. Para se obter essas prevalências nos modelos mono- e digênicos a freqüência dos alelos causais variaram em função do modelo genético e da combinação dos demais parâmetros envolvidos. Esses parâmetros foram combinações de 50, 80 e $100 \%$ de penetrância com proporções de 0,20 e $50 \%$ de fenocópias, em cada prevalência. Genótipos de pais e filhas foram simulados e os fenótipos inicialmente atribuídos de acordo com o modo de herança. Posteriormente, para simular penetrância incompleta, a proporção apropriada de indivíduos com o genótipo para doente ou positivo foram casualmente designados negativos, sendo a proporção de fenocópias obtida de forma inversa. Nos modelos mistos a susceptibilidade das filhas foi simulada a partir do valor genético do pai e um componente residual. A herdabilidade variou de 0,1 a 0,6 e um gene de efeito maior foi modelado para responder por 20,50 ou $80 \%$ da variância genética. Limiares foram fixados para as diversas prevalências e descendentes com valores na escala base superiores ao limiar considerados positivos.

A relação de risco foi definida como sendo a razão entre o risco de um parente de um indivíduo afetado adoecer e a prevalência populacional. Esse conceito foi introduzido por James (1971) e Risch (1990a) e adaptado para a estrutura familiar de meios-irmãos, tipicamente encontrada em bovinos, por Thaler Neto et al. (2000). Para um par de meios-irmãos $X_{1}$ e $X_{2}$, com fenótipos 1 (afetado) ou 0 (não afetado), o risco de um parente de um indivíduo afetado é definido como sendo $\mathrm{K}_{\mathrm{R}}=\mathrm{E}\left(\mathrm{X}_{2} \mid \mathrm{X}_{1}=1\right)$ ) e a prevalência populacional como $\mathrm{K}_{\mathrm{P}}=\mathrm{E}\left(\mathrm{X}_{1}\right)$. Assim, $\lambda_{R}$ é estimada pela equação:

$\lambda_{\mathrm{R}}=\frac{\mathrm{K}_{\mathrm{R}}}{\mathrm{K}_{\mathrm{P}}}=1+\frac{\operatorname{Cov}\left(\mathrm{X}_{1,} \mathrm{X}_{2}\right)}{\mathrm{K}_{\mathrm{P}}^{2}}($ Risch, 1990a $)$

Detalhes sobre a estimação de $\lambda_{R}$ encontram-se em Thaler Neto et al. (2000).

A análise de ligação gênica foi baseada em pares de meios-irmãos afetados. Para cada touro foram simulados acasalamentos com vacas não aparentadas. Foram incluídas todas as famílias com, no mínimo, dois descendentes afetados, sendo analisados todos os meios-irmãos afetados. O número de descendentes por touro simulados visou uma média de cinco meios-irmãos positivos por família. Para o modelo monogênico recessivo foram adicionalmente simulados dados para famílias com número médio de três e 10 indivíduos positivos.

Para cada touro e seus descendentes foi gerado um segmento de cromossomo de 90 centimorgans (cM), com 10 marcadores genéticos uniformente espaçados em $10 \mathrm{cM}$, com cinco alelos de mesma freqüência. Um QTL bialélico (modelos mono- e digênicos) ou um gene de efeito maior (modelos mistos) foi posicionado no centro do cromossomo simulado. Nos modelos digênicos foram simulados dois cromossomos, sendo posicionado um gene causal em cada.

A análise de ligação gênica foi procedida mediante métodos estatísticos não paramétricos que analisam se o padrão de herança de uma região de cromossomo concorda com herança mendeliana ao acaso. Utilizaram-se pares de meios-irmãos afetados (affected sib pairs - ASP), analisando-se a identidade dos alelos dos meiosirmãos por descendência ou identical by descent (IBD). Nesse método, a indicação da presença de um QTL resulta de uma proporção de alelos IBD (entre os pares de irmãos) maior que $50 \%$, valor esperado para segregação independente (Lander, Schork, 1994; Terwilliger, Ott, 1994; Ghosh, Collins, 1996). Marcadores genéticos localizados 
próximos foram analisados em conjunto, empregando-se metodologia de multipoint analysis, sendo a análise estatística procedida a cada $1 \mathrm{cM}$. Para cada posição $\mathrm{x}$ do cromossomo, foi calculado o número de alelos IBD $\pi(\mathrm{x}) \mathrm{em}$ famílias com s meios-irmãos positivos para todos os $\mathrm{s}(\mathrm{s}-1) / 2$ possíveis pares, a partir das $\mathrm{n}_{\mathrm{ij}}(\mathrm{x})$ cópias IBD dos meios-irmãos positivos ij, de acordo com Lander e Schork (1994), sendo:

$$
\pi(x)=\sum_{i=1}^{s-1} \sum_{j=i+1}^{s} n_{i j}(x)
$$

O resultado de todas as famílias analisadas foi combinada em uma soma П(x). Para famílias com mais de dois meios-irmãos, a contribuição de cada família foi balanceada com o fator $2 / \mathrm{s}$, de forma análoga a Suarez e Hodege (1979). A partir da soma $\Pi(\mathrm{x})$ foram aplicados dois testes estatísticos. Um teste foi um lod score não paramétrico (lod), desenvolvido por Risch (1990b), para pares de irmãos afetados. O outro método utilizado foi um teste padrão de $\chi^{2}$ com um grau de liberdade, desenvolvido para análise de IBD no programa estatístico ESPA (Terwilliger, Ott (1994).

O poder do teste foi definido como a proporção de 500 repetidas simulações de dados, que ultrapassaram o valor crítico. Para o lod score foi utilizado um limiar de significância igual a 3.0, recomendado por Morton (1998). A partir desse valor chega-se a um $\chi^{2}$ de 3.816 . Esses valores foram testados para o presente trabalho mediante simulação de dados sob a hipótese de nulidade de ausência de QTL. Foi estimado o número necessário de famílias para alcançar um poder de $80 \%$ de detecção do QTL e no modelo de um locus recessivo adicionalmente para 90\%. Quando não se alcançava esse valor, o número de famílias era aumentado até atingir a meta estabelecida.

\section{RESULTADOS E DISCUSSÃO}

O número de famílias necessário para atingir a probabilidade de $80 \%$ de se encontrar o gene causal para uma característica sob modelo monogênico recessivo, com diferentes prevalências, penetrâncias e proporções de fenocópias, encontra-se na Tab. 1. O número necessário de famílias genotipadas variou de 18 até 510. O primeiro valor corresponde a uma característica mendeliana simples com $5 \%$ de prevalência. O último refere-se a $20 \%$ de prevalência, com baixa penetrância e alta proporção de fenocópias, situação esta em que $\lambda_{R}$ se aproxima de 1, valor correspondente à hipótese de nulidade.

Tabela 1. Número necessário de famílias (média de cinco meios-irmãos afetados) para identificar, com probabilidade de $80 \%$, um monogene recessivo, em função da prevalência, da penetrância e da proporção de fenocópias

\begin{tabular}{|c|c|c|c|c|c|c|c|}
\hline \multirow{3}{*}{ Pen $^{1}$} & \multirow{3}{*}{$\mathrm{Fen}^{2}$} & \multicolumn{6}{|c|}{ Prevalência } \\
\hline & & \multicolumn{2}{|l|}{$5 \%$} & \multicolumn{2}{|l|}{$10 \%$} & \multicolumn{2}{|l|}{$20 \%$} \\
\hline & & $\begin{array}{l}\text { Número de } \\
\text { famílias }\end{array}$ & $\lambda \mathrm{R}^{3}$ & $\begin{array}{l}\text { Número de } \\
\text { famílias }\end{array}$ & $\lambda \mathrm{R}^{3}$ & $\begin{array}{l}\text { Número de } \\
\text { famílias }\end{array}$ & $\lambda \mathrm{R}^{3}$ \\
\hline \multirow{2}{*}{1.0} & 0 & 18 & 2.77 & 22 & 2.09 & 38 & 1.62 \\
\hline & $50 \%$ & 80 & 1.64 & 120 & 1.41 & 246 & 1.24 \\
\hline \multirow{2}{*}{0.5} & 0 & 24 & 2.10 & 40 & 1.61 & 100 & 1.29 \\
\hline & $50 \%$ & 120 & 1.40 & 225 & 1.25 & 510 & 1.13 \\
\hline
\end{tabular}

penetrância; ${ }^{2}$ proporção de fenocópias; ${ }^{3}$ relação de risco para a respectiva combinação de parâmetros.

A probabilidade de se encontrar um gene para uma característica binária é influenciada pela sua prevalência. Mantidas as demais condições, a identificação de um gene é mais trabalhosa em características de aparecimento freqüente em relação às mais raras (Tab. 1 e Fig. 1). Isto se deve à maior freqüência do alelo causal em características de prevalência elevada, o que determina maior proporção de pais homozigotos, cujos filhos não irão trazer nenhuma informação relativo à proporção de IBD nos marcadores genéticos ligados ao alelo causal. Smaley et al. (1996) também mostraram, em uma série de modelos genéticos, que a probabilidade de 
mapear um gene diminui à medida em que aumenta a freqüência do gene causal. Na Fig. 1 observa-se que à medida em que aumenta a prevalência cresce o número necessário de animais genotipados, enquanto a relação de risco
$\left(\lambda_{R}\right)$ diminui. Dessa forma, para características sob modelo genético idêntico, porém com prevalências diferentes, $\lambda_{R}$ pode ser empregado como indicador do número necessário de famílias genotipadas.

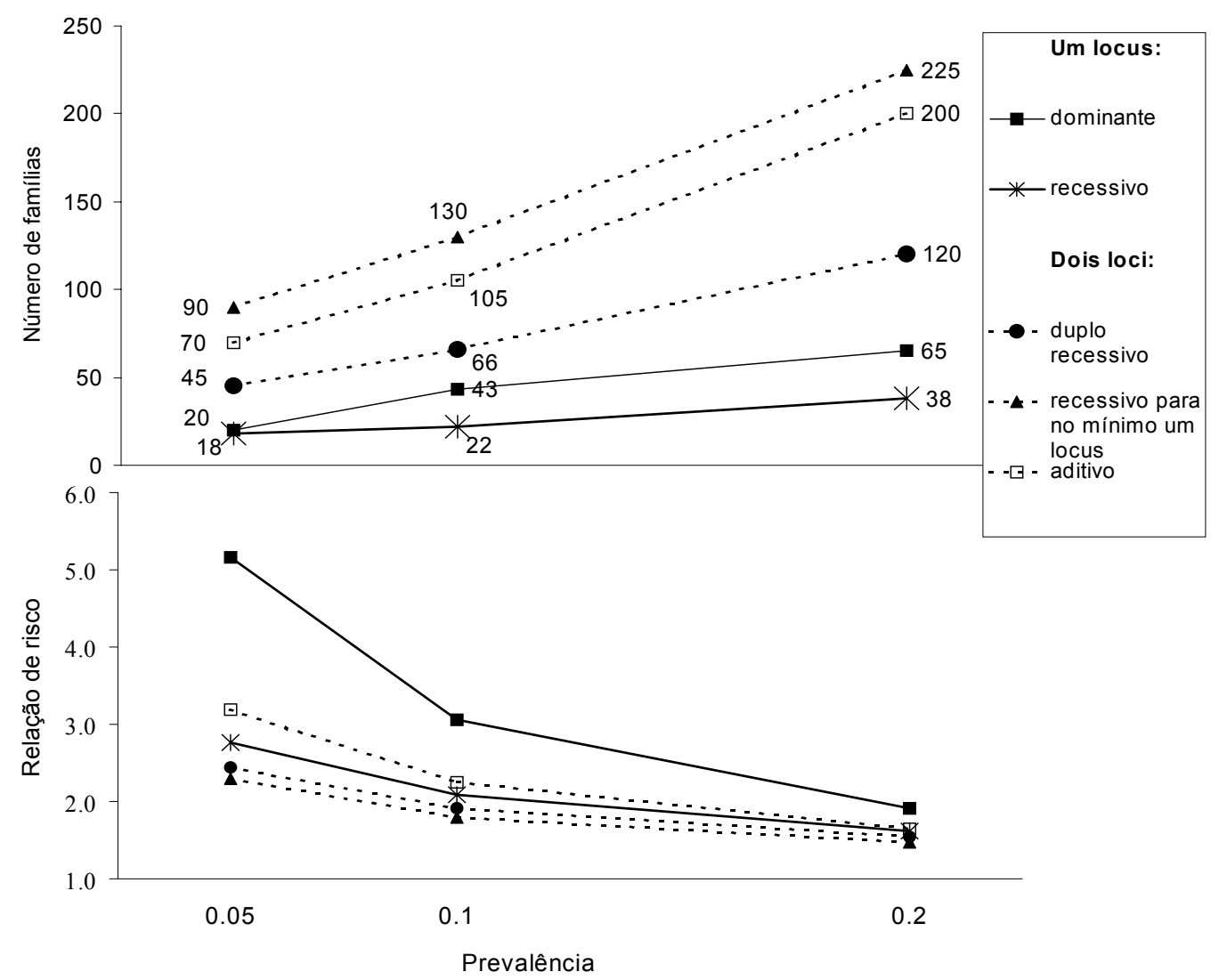

Figura 1. Relação de risco $\left(\lambda_{R}\right)$ e número necessário de famílias genotipadas para o mapeamento de características mono- (-) e digênicas (--), com probabilidade de $80 \%$, em função da prevalência. Modelos com penetrância completa e sem fenocópias.

Em modelos mono- e digênicos proporções elevadas de fenocópias aumentam consideravelmente o número necessário de animais genotipados (Fig. 2). Nesse caso parte dos indivíduos afetados não recebe alelo causal dos pais, o que resulta em probabilidade de IBD correspondente ao esperado sob a hipótese de nulidade. $\mathrm{O}$ aumento da proporção de fenocópias também determina redução da $\lambda_{R}$ (Tab. 1), porém menos drástica. Dessa forma, a ausência de informações sobre a proporção de fenocópias na característica pode determinar subestimação do número de animais a serem genotipados, a partir dos valores estimados de $\lambda_{\mathrm{R}}$. Em características com elevada proporção de fenocópias o desenvolvimento de fenótipos mais específicos pode ser uma alternativa importante para viabilizar o mapeamento genético (Ghosh, Collins, 1996; Brzustowicz, 1998). 


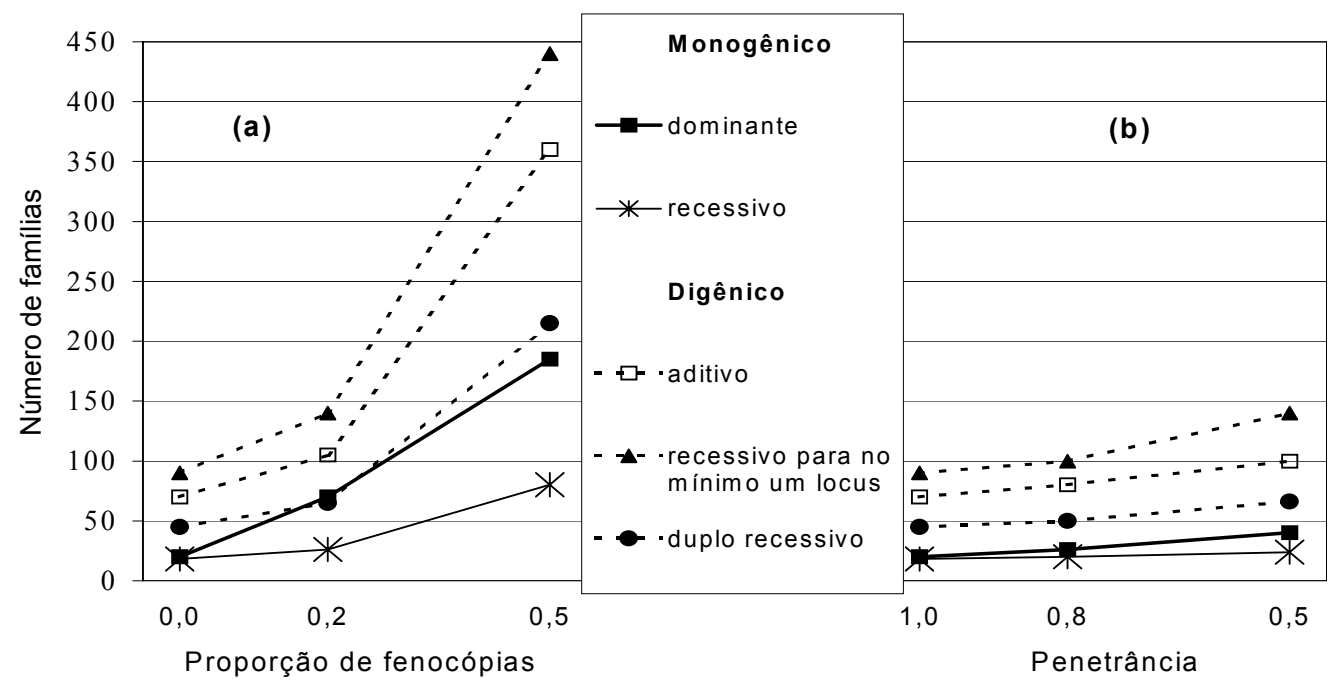

Figura 2. Influência da proporção de fenocópias (a, modelo com penetrância completa) e da penetrância (b, modelo sem fenocópias) sobre o número necessário de famílias genotipadas (média de 5 meios-irmãos afetados) para mapear características mono- (-) e digênicas (--), com probabilidade de $80 \%$. Característica com $5 \%$ de prevalência.

A influência da penetrância sobre a necessidade de animais genotipados é relativamente pequena (Tab. 1 e Fig. 2), assim como também ocorre pequena variação nas estimativas de $\lambda_{R}$ nos casos de penetrância incompleta. Isto faz com que $\lambda_{R}$ seja um indicador apropriado para $\mathrm{o}$ delineamento de experimentos de mapeamento de genes com penetrância incompleta, o que concorda com deduções matemáticas conduzidas por Risch (1990b). Para uma determinada freqüência do alelo causal a penetrância não afeta os genótipos dos indivíduos afetados e, conseqüentemente, o poder do teste em detectar ligação entre gene e marcador genético.

Na Fig. 3 é apresentada a relação entre $\lambda_{R}$ e o número necessário de animais genotipados para uma característica monogênica recessiva, baseada nos dados de todas as prevalências (5, 10 e $20 \%)$, níveis de penetrância (100, 80 e 50\%) e proporções de fenocópias estudadas $(0,20 \mathrm{e}$ $50 \%$ ). As estimativas demonstram que, independentemente dos parâmetros analisados, o número de animais genotipados pode ser estimado grosseiramente a partir da relação de risco. Pode-se observar também que, para aumentar a probabilidade de deteç̧ão do ETL de 80 para $90 \%$, o aumento no número de animais genotipados é proporcional nas diferentes combinações de parâmetros analisadas, da ordem de 15 a $20 \%$.

Em comparação com a herança monogênica recessiva, o mapeamento de genes para características dominantes exige maior número de famílias genotipadas (Fig. 1 e 2), sendo esta diferença mais acentuada em características de elevada prevalência. Por exemplo, para prevalência de $20 \%$ o número de famílias aumenta em 1,7 vezes em relação ao modelo recessivo, para $5 \%$ de prevalência, em 1,1 vezes, sendo desprezível o aumento para $1 \%$ de prevalência (dados não apresentados). Em famílias de meios-irmãos um indivíduo pode ser positivo para uma característica dominante em função de um alelo causal herdado da mãe não genotipada, o que determina valores de IBD esperados sob a hipótese de nulidade. Dessa forma, apesar de valores mais elevados de $\lambda_{R}$ para características com herança dominante, elas são mais difíceis de mapear em famílias de meios-irmãos. $O$ emprego de $\lambda_{R}$ como indicador do número necessário de animais genotipados em famílias de meios-irmãos somente é eficiente quando alguma informação sobre a base genética da característica estiver disponível. De acordo com o trabalho de Smaley et al. (1996), para irmãos completos as diferenças entre os dois modelos não são relevantes. 


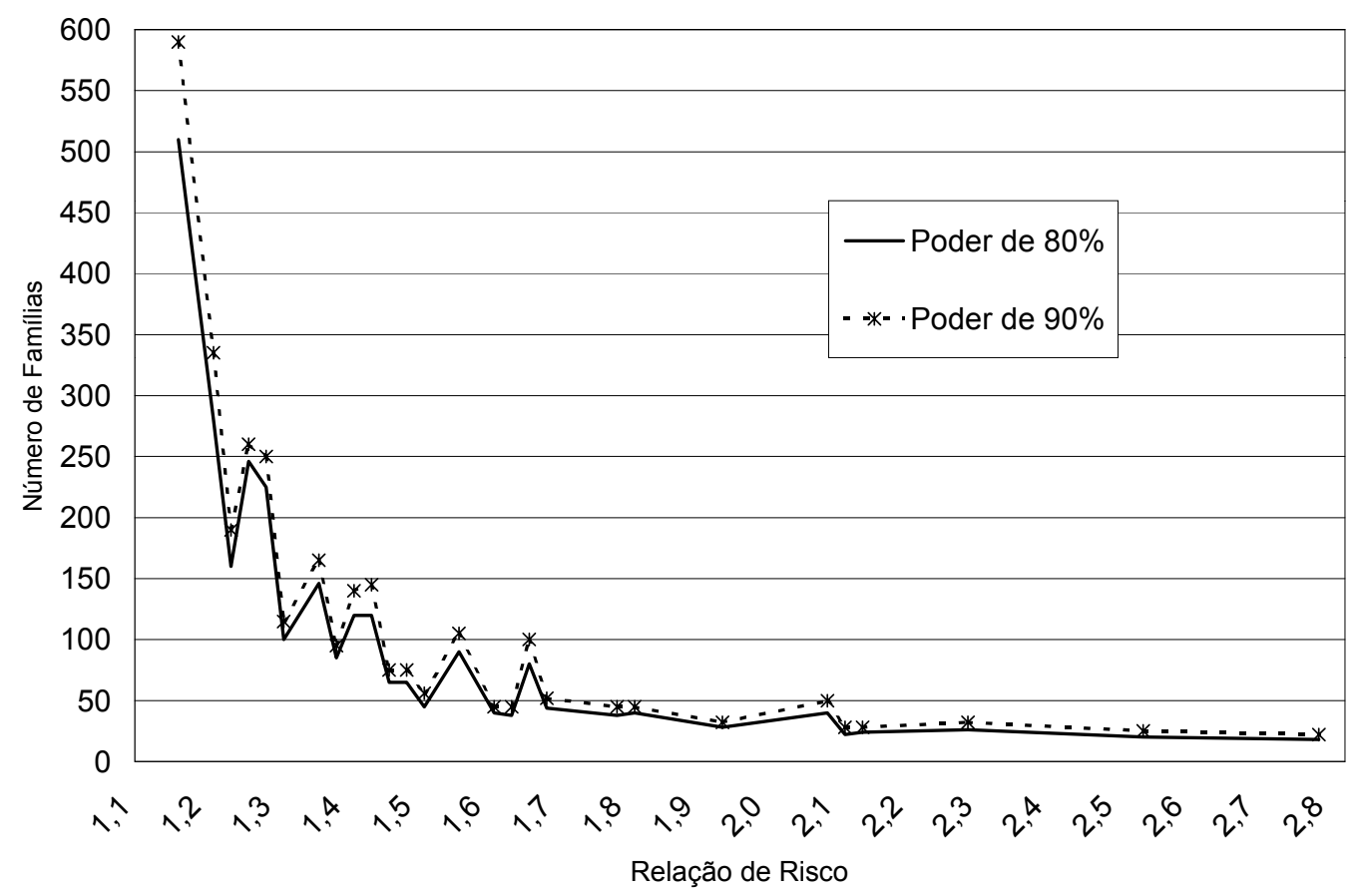

Figura 3. Número necessário de famílias genotipadas para o mapeamento de genes para uma característica monogênica recessiva, com probabilidade de 80 e $90 \%$, em função da relação de risco $\left(\lambda_{R}\right)$.

A presença de um segundo locus influenciando uma característica diminui a probabilidade de mapeamento genético (Fig. 1 e 2), o que concorda com os trabalhos de Risch (1990) e Smaley (1996) para irmãos completos. Nos modelos digênicos o incremento no delineamento experimental necessário supera proporcionalmente a redução de $\lambda_{R}$. A influência de um segundo locus é menor em modelos duplamente recessivos, nos quais necessariamente uma cópia dos alelos causais deverá ser originada do pai, sendo maior nos modelos em que o indivíduo pode ser afetado em função de um único alelo localizado em um dos loci envolvidos (heterogeneidade genética). Nessas características o mapeamento genético também é dificultoso em famílias de irmãos completos (Risch, 1990b; Lander, Schork, 1994; Smaley et al., 1996; Terwilliger, Weiss, 1998). Uma alternativa visando possibilitar o mapeamento genético nessas condições encontra- se na subdivisão de um fenótipo em componentes mais específicos, os quais podem estar sendo influenciados pelos diferentes loci (Brzustowicz, 1998).

A Fig. 4 mostra o número necessário de famílias genotipadas para características sob modelos mistos, com gene de efeito maior recessivo e dominante, em função da herdabilidade e da influência do gene de efeito maior sobre a variação genética. A probabilidade de mapeamento de um gene de efeito maior aumenta com a herdabilidade e com a influência dele sobre a variabilidade genética, de modo que, à medida em que esses parâmetros se elevam, as estimativas do número necessário de animais a serem genotipados e de $\lambda_{R}$ se aproximam daquelas estimadas para os respectivos modelos monogênicos recessivo e dominante. Nesse caso, não é necessário diferenciar entre modelos monogênico e misto para utilizar $\lambda_{\mathrm{R}}$ como 
indicador do número de animais a serem genotipados. Aumento na probabilidade de mapeamento de genes à medida em que aumenta a herdabilidade também foi observado por
Martinez et al. (1998) em estudos de simulação para características quantitativas em famílias de meios-irmãos.

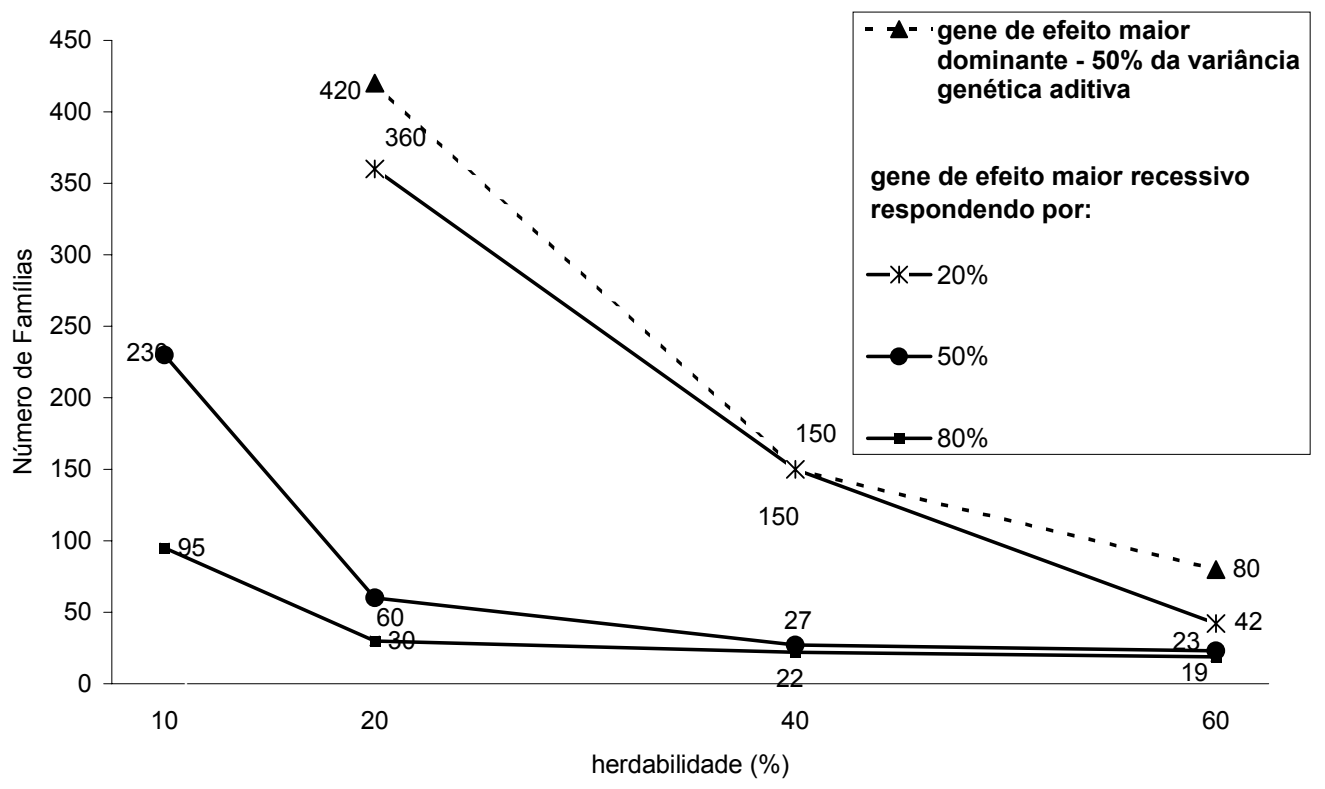

Figura 4. Número necessário de famílias genotipadas para o mapeamento de genes em características sob modelos genéticos mistos, com $80 \%$ de probabilidade, em função da herdabilidade e da ação de um gene de efeito maior.

O aumento do tamanho das famílias de meiosirmãos reduz significativamente o número total de indivíduos a serem genotipados (Fig. 5) para um modelo monogênico recessivo com penetrância completa e sem fenocópias. Mediante aumento de três para 10 indivíduos afetados genotipados por família o número total de indivíduos genotipados pode ser reduzido em aproximadamente $45 \%$. Este resultado mostra-se interessante em bovinos, nos quais grandes famílias de meios-irmãos estão disponíveis em função do emprego da inseminação artificial.

\section{CONCLUSÕES}

A partir das simulações conclui-se que, no delineamento de experimentos para $o$ mapeamento genético de características binárias complexas, a estimação da relação de risco é um instrumento importante na indicação do número necessário de meios-irmãos a serem genotipados, especialmente quando existe algum conhecimento sobre o modelo de herança da característica. Quando dois ou mais loci estão envolvidos com um determinado fenótipo, ou quando a influência ambiental é bastante significativa, uma definição mais detalhada da característica a ser analisada, aproximando-se da sua base biológica, pode ser necessária para possibilitar o mapeamento dos genes envolvidos. Em características com herança dominante geralmente o número de animais a serem genotipados é bastante elevado. Para o mapeamento desses genes outras estruturas familiares (ex: irmãos completos) são mais indicadas. A utilização de famílias com grande número de animais afetados pode reduzir consideravelmente os custos de genotipagem. 

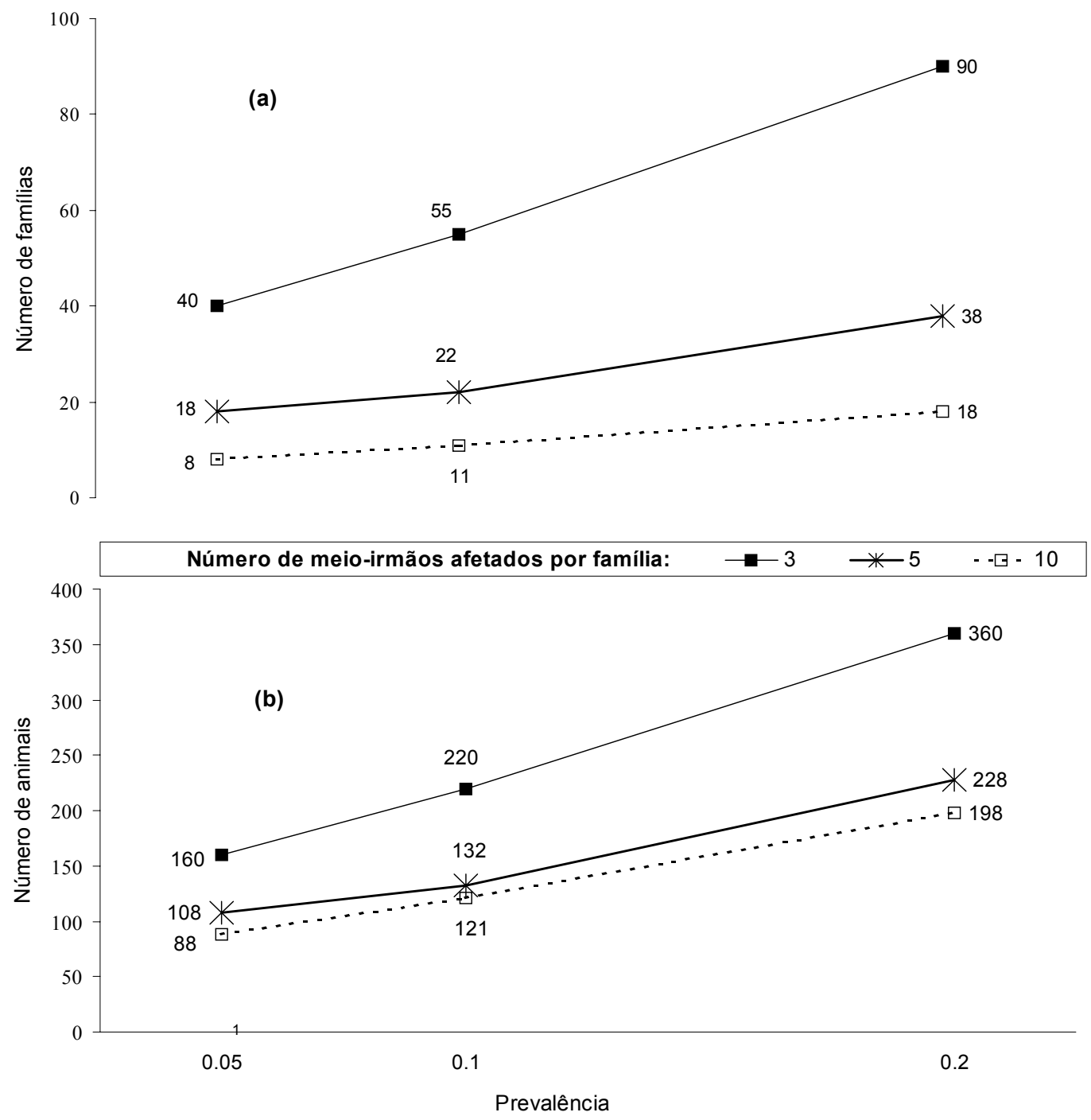

Figura 5. Influência do número de animais genotipados por família (3, 5 ou 10 meios-irmãos afetados) sobre o número necessário de famílias de meios-irmãos genotipadas (a) e o número total de indivíduos genotipados (descendentes e pai) (b) para o mapeamento de uma característica monogênica recessiva com diferentes prevalências.

\section{REFERÊNCIAS BIBLIOGRÁFICAS}

BRZUSTOWICZ, L.M. Molecular genetic approaches to the study of language. Human Biol., v.70, p.325-345, 1998.
FALCONER, D.S.; MACKAY, T.F.C. Introduction to quantitative genetic. 4.ed. London: Longman, 1996. 464p.

GHOSH, S.; COLLINS, F.S. The geneticist's approach to complex disease. Ann. Rev. Medic., v.47, p.333-353, 1996. 
GIANOLA, D.; FOULLEY, J.L. Sire evaluation for ordered categorical data with a threshold model. Gen. Select. Evol., v.15, p.201-223, 1983.

GU, C.; RAO, D.C. A linkage strategy for detection of human quantitative-trait loci. II. Optimization of study designs based on extreme sib pairs and generalized relative risk ratios. Am. J. Human Genet., v.61, p.211-222, 1997.

HODGE, S.E. The information contained in multiple sibling pairs. Genet. Epidemiol., v.1, p.109-122, 1984.

HOESCHELE, I.; TIER, B. Estimation of variance components of threshold characters by marginal posterior models and means via Gibbs sampling. Genet. Select. Evol., v.27, p.519-540, 1995.

JAMES, J.B. Frequency in relatives for an all-ornone-trait. Ann. Human Genet., v.35, p.47-49, 1971.

KRUGLYAK, L.; LANDER, E.S. Complete multipoint sib-pair analysis of qualitative and quantitative traits. Am. J. Human Genet., v 57, p.439-454, 1995.

LANDER, E.S.; SCHORK, N. Genetic dissection of complex traits. Science, v.265, p.237-247, 1994.

LUI, K.J.; MAYER, J.A.; ECKHARDT, L. Confidence interval for the risk ratio under cluster sampling based on the beta binomial model. Statist. Med., v.19, p.2933-42, 2000.

MARTINEZ, M.L.; VUKASINOVIC, N.; FREEMAN, A.E. Estimating QTL location and QTL variance in half-sib families under random model with missing parental genotypes. J. Anim. Breed. Genet., v.115, p.165-180, 1998.

MORTON, N.E. Significance levels in complex inheritance. Am. J. Human Genet., v.62, p.690697, 1998.

RISCH, N. Linkage strategies for genetically complex traits. 1. Multilocus models. Am. Human Genet., v.46, p.222-228, 1990a.

RISCH, N. Linkage strategies for genetically complex traits. 2. The power of affected relative pairs. Am. Human Genet., v.46, p.229-241, 1990b.

SMALEY, S.; WOODWARD, J.A.; PALMER, C.G.S. A general statistic model for detecting complex-trait by using affected relative pairs in a genome search. Am. Human Genet., v.58, p.844860, 1996.

SUAREZ, B.K.; HODGE, S.E. A simple method to detect linkage for rare recessive diseases: an application to juvenile diabetes. Clin. Genet., v.15, p.126-136, 1979.

TERWILLIGER, J.D.; OTT, J. Handbook of human genetic linkage. Baltimore: Johns Hopkins, 1994. 307p.

TERWILLIGER, J.D.; WEISS, K.M. Linkage disequilibrium mapping of complex disease: fantasy or reality? Current Opin. Biotechnol., v.9, p.578-594, 1998.

THALER NETO, A.; FRIES, R.; THALLER, G. Risk Ratio as parameter for the genetic characterization of complex binary traits in cattle. A simulation study under various genetic models using halfsib families. J. Anim. Breed. Genet., v.117, p.153-167, 2000. 